\title{
Exploring Insights of an Evaluation of a Meteorology \& Oceanography Program for Training Navy Officers
}

\author{
Wayne Aaberg (Corresponding author) \\ Department of Professional Development \\ 5901 NCBC $5^{\text {th }}$ Street, Bldg. 461, Gulfport, MS, 39501, United States \\ Tel: 1-850-499-1965_E-mail: aabergw@cableone.net

\begin{abstract}
Carla Thompson
Dept. of Research and Advanced Studies, University of West Florida 11000 University Parkway, Pensacola, Florida 32514, United States

Tel: 1-850-473-7327_E-mail: cthompson1@uwf.edu
\end{abstract}

\author{
Mark Shaffer \\ Department of Professional Development \\ 5901 NCBC $5^{\text {th }}$ Street, Bldg. 461, Gulfport, MS, 39501, United States
}

Tel: 1-228-224-4577 E-mail: agc409@bellsouth.net

Received: December 12, 2012 Accepted: December 29, 2012

doi:10.5296/ber.v3i1.3322 URL: http://dx.doi.org/10.5296/ber.v3i1.3322

\begin{abstract}
The evaluation of training programs to determine effective strategies for improving performance is a priority in business and military environments. Improved performance is a paramount interest for organizations dependent on training for preparing employees. This evaluation study consisted of a one-group pre-posttest quantitative research design with $\mathrm{N}=45$ participants completing a pre-assessment prior to entering the Basic Oceanography Accession Training course and a posttest assessment upon completion of the course. Study participants were comprised of Navy officers who had earned at least a baccalaureate degree prior to beginning the program and their major academic focus was one or more of the following areas:
\end{abstract}


meteorology, marine science, oceanography, chemistry, biology, nuclear engineering, physics, geology, and geography. Four research questions guided the study and include: (1) Is there a significant mean change in the positive direction from pretest to Basic Oceanography Accession Training test scores for each of the subscales identified on the Basic Oceanography Accession Training test instrument used in the study?; (2) Is there a significant mean difference between males and females on the various posttest subscales of the Basic Oceanography Accession Training test when pretest differences are controlled?; (3) Is there a difference in mean posttest subscale scores for the various academic majors of participants and by gender?; and (4) Is there a relationship between length of service (in years) and posttest scores of the participants? Implications for businesses and military environments grappling with evaluating employee training effectiveness are provided. Insights for future research efforts in routinely assessing training programs are highlighted.

Keywords: Evaluation, Training programs, Effective strategies for improving performance

\section{Introduction}

The evaluation of training programs to determine effective strategies for improving performance is a priority in business and military environments. Assessment methods used in the evaluation of training programs measure performance in knowledge-based training, skills-based training, and/or long-term development training programs. Improved performance is a paramount interest for organizations dependent on training for preparing employees. Sentric Competency Management Company (2010) summarizes the need for evaluating training programs "each year globally many millions of dollars are spent on training. It would seem reasonable to establish just how effective this training has been if only to justify the budget" (para. 1). Stern (2011) reports "92 out of 96 Fortune 500 CEOs said they are most interested in learning the business impact of their [training] and development programs, but only $8 \%$ see that happening at their companies now" (para. 9). John C. Robak, Chief Operations Officer for Chicago-based, Greely and Hansen Company said "organizations have traditionally treated training as a cost and expense. When training has a sufficient payback, it can be viewed as an investment, not an expense" (Stern, 2011, para. 17). Hamid (2011) concurs "that organizations with more progressive people-oriented policies (training programs) have excelled, leaving the competition behind" (p. 72), but according to the American Society for Training \& Development (2009), "companies employ a myriad of strategies to identify and quantify the results of training, ... most are not satisfied with the evaluation efforts" (p. 3).

The current evaluation study explored the investment in assessing training programs within a military environment. The study focused on using quantitative research methodology for designing high quality evaluation plans, thereby producing rigorous empirical outcomes. Insights provided by study results are offered for military and business environments to examine benefits and concerns associated with evaluation of training programs.

\section{Literature Review}

A review of literature focused on the evaluation of training programs indicates that a number of 
companies have supported a wide variety of procedures and analyses to evaluate training (Bedingham, 1997; Bramley \& Kitson, 1994; Clements \& Josiam, 1995; Kirkpatrick, 1994). Researchers (Rae, 2010) suggest there are many different ways to assess training and learning. Feedback and test results assist organizations and provide gauges of progress related to learning. Feedback may also encourage learner confidence and increase learner skill levels as well as improve workforce development training efforts.

Chmielewski and Phillips (2002) recognize Kirkpatrick's Four-Level Evaluation model as "both helpful and instructive in understanding how to best capture program impact" (p. 226). Additionally, researchers reporting in HR People (2012) champion Kirkpatrick's Four-Level Evaluation Model as an industry standard across human resources and training communities. The Kirkpatrick Evaluation Model (2009, p. 3) was utilized in the current study. The basic structure of the Kirkpatrick Model includes four levels: (a) Level 1 (Reaction) addresses to what extent did the participants find the training useful; (b) Level 2 (Learning) responds to what extent did participants improve knowledge and skills and change attitudes as a result of the training; (c) Level 3 (Behavior) examines to what extent did participants change their behavior back in the workplace as a result of the training; and (d) Level 4 (Results) focused on what measurable organizational benefits resulted from the training in terms of productivity, efficiency, and sales revenue.

Another area of literature focus relevant to the current study emphasizes core competencies within the context of training evaluation. Kerchner, Hardwick, and Thornton (2012) suggest "a growing emphasis on the use of core competencies to design and inform curricula" (p. A27). The Department of the Navy institutionalized the Navy Leadership Competency Model and explains;

A competency is defined as a behavior or set of behaviors that describes excellent performance in a particular work context (Job, Role, Position, or Function). These characteristics are applied to provide clarification of standards and expectations and exemplify what superior performers do more often, with better on-the-job results (Center for Personal and Professional Development, 2012).

Core competencies established within the military arena are initiated by the Chairman of the Joint Chiefs of Staff (2011) who distributes a Universal Joint Task List (UJTL) to support joint, capabilities-based planning and joint training and education. The UJTL also serves as a master menu of tasks, from which the Navy develops the Universal Navy Task List (UNTL). The UNTL "contains a comprehensive hierarchical listing of tasks that can be performed by a naval force, the conditions under which those tasks may be performed, and the standards to which task performance shall be measured" (p. 1-1). A secondary level of task analysis (Job, Duty, Task Analysis or JDTA) is then performed specific to an individual job to obtain specific learning objectives involved in the establishment of training activities. Testing programs are designed to assess specific learning objectives and to measure achieved learning outcomes aligned with essential tasks as outlined by the JDTA (Naval Education and Training M-132A, 2010). The use of these procedures as documented in the literature for determining the core competencies used within military environments and in particular the Navy was a critical 
preliminary component for accomplishing the current evaluation study.

\section{Description of the Study}

The purpose of the study was to deliver an evaluation research project of a training program aimed at preparing Navy officers for working in the fields of meteorology and oceanography. The description of the evaluation study includes the following focus areas: (a) the setting; (b) a description of the study participants; (c) the research design; (d) the research questions and hypotheses; (e) the instrumentation used in the data collection; (f) the analysis of data procedures; and (g) study results. Each of these focus areas is presented with appropriate discussion and description.

\subsection{Setting}

This command utilizes the Department of Defense (DOD) instructional systems design and testing program as well as Kirkpatrick's Four-Level Evaluation Model to assess the effectiveness of specific training programs. The current study focused on one particular course of instruction and training, a seven-week Basic Oceanography Accession Training course. The purpose of the Navy Basic Oceanography Officer Accession Training course is to introduce new Naval Oceanography candidates into the mission, functions, and tasks of the Naval Meteorology and Oceanography Command, as well as to provide the knowledge, skills, and experiences required to manage the production of environmental support products used to enhance decision-making capabilities in strategic, operational, and tactical theaters of war. The Basic Oceanography Accession Training course is considered to be a beginning course within the programs of study offered by this command.

\subsection{Participants}

The academic and naval experience backgrounds of the Basic Oceanography Accession Training course student participants are widely variable ranging from little or no background to several years of military experience as well as previous civilian experience. The length of service of the Basic Oceanography Accession Training course participants ranged from one year of active duty naval service to more than 15 years of active service. Basic Oceanography Accession Training course participants in the study were comprised of Navy officers who had earned at least a baccalaureate degree prior to beginning the program and their major academic focus was one or more of the following areas: meteorology, marine science, oceanography, chemistry, biology, nuclear engineering, physics, geology, and geography. Basic Oceanography Accession Training course participants have elected to enter the Navy Oceanography program through one of two pathways: (1) direct accession from the United States Naval Academy or Officer Candidate School or (2) lateral transfer from the Naval Air Force, Naval Surface Force, or Naval Submarine Force. A total of N= 45 Basic Oceanography Accession Training students participated in the evaluation study.

\section{Research Design}

The evaluation study consisted of a one-group pre-posttest quantitative research design with study participants completing a pre-assessment prior to entering the Basic Oceanography 
Accession Training course and a posttest assessment upon completion of the Basic Oceanography Accession Training course. Specific variables assessed during the study include the independent demographic variables of gender, academic category code (ACC), and time in service and the dependent variable of change in mean scores from pre to posttest assessment. The treatment for the study consisted of the Basic Oceanography Accession Training course comprised of a 7-week intensive training program designed to prepare Navy Officers with the knowledge, skills, and experiences suitable for the production of environmental support products and appropriate learning outcomes for enhancing students' decision-making capabilities in strategic, operational, and tactical theaters of war.

\section{Research Questions and Hypotheses}

Four research questions guided the study. Specific research questions and hypotheses were generated from the study purpose and guiding framework influences of the Kirkpatrick Evaluation Model and the naval core curriculum considerations. Each research question is listed with the appropriate research hypothesis and null hypothesis statements.

\subsection{Research Question One}

The first research question with the associated hypothesis and null hypothesis are presented in this first section. Research Question One: Is there a significant mean change in the positive direction from pretest to posttest test scores for each of the subscales identified on the Test instrument used in the study? Hypothesis One: There is a significant mean change in the positive direction from pretest to posttest test scores for each of the subscales identified on the Basic Oceanography Accession Training test instrument used in the study. Null Hypothesis One: There is no significant mean change in the positive direction from pretest to posttest test scores for each of the subscales identified on the Basic Oceanography Accession Training test instrument used in the study.

\subsection{Research Question Two}

The second research question addressed in the study with the associated hypothesis and null hypothesis are presented in this second section. Research Question Two: Is there a significant mean difference between males and females on the various posttest subscales of the Basic Oceanography Accession Training test when pretest differences are controlled? Hypothesis Two: There is a significant mean difference between males and females on the various posttest subscales of the Basic Oceanography Accession Training test when pretest differences are controlled. Null Hypothesis Two: There is no significant mean difference between males and females on the various posttest subscales of the Basic Oceanography Accession Training test when pretest differences are controlled.

\subsection{Research Question Three}

The third research question investigated by the study with associated hypothesis and null hypothesis are presented in this section. Research Question Three: Is there a difference in mean posttest subscale scores for academic majors of the participants by gender? Hypothesis Three: (a) There is a main effect mean difference in posttest subscale scores for Academic Category 


\section{MInstitute ${ }^{\text {Macrothink }}$}

Business and Economic Research ISSN 2162-4860

Code (ACC) when gender is also considered; (b) There is a main effect mean difference in posttest subscale scores for gender when academic major (ACC) is also considered; and (c) There is an interaction effect in mean differences when academic majors (ACC) and gender are considered simultaneously. Null Hypothesis_Three: (a) There is no main effect mean difference in posttest subscale scores for academic majors (ACC) when gender is also considered; (b) There is no main effect mean difference in posttest subscale scores for gender when academic major (ACC) is also considered; and (c) There is no interaction effect in mean differences when academic majors (ACC) and gender are considered simultaneously.

\subsection{Research Question Four}

The fourth research question identified for investigation with the associated hypothesis and null hypothesis are presented in this section. Research Question Four: Is there a relationship between length of service (in years) and posttest test scores of the $\mathrm{N}=45$ participants? Hypothesis Four: There is a relationship between length of service (in years?) and posttest test scores. Null Hypothesis Four: There is no relationship between length of service (in years) and posttest test scores.

\section{Instrumentation}

The pre and posttest assessments were constructed of 50 questions each and consist of parallel forms of statistically the same items (identical conceptually and statistically) in both the pre and posttest assessments. Eight sub-scales comprise the pre and posttest assessments used in the study:

- Meteorological Satellite

- Weather Surveillance Radar 1988-Doppler

- Skew-T Log P Diagram

- Surface Weather Observations

- Environmental Codes

- Atmospheric Physics and Dynamics

- Numerical Weather Prediction

- Forecasting Weather Elements and Convective Severe Weather

The questions align to specific learning objectives addressed throughout the course, are selected based on their criticality to performance of a job-specific requirement, and include questions designed to measure a student's mastery of the learning objectives (Naval Education and Training M-132A, 2010, p. 2-3).

\subsection{Reliability Discussion}

Data collected from Basic Oceanography Accession Training students' pre-assessment and posttest assessment scores from previous course offerings were used to conduct reliability and validity analyses for the pre-posttest Basic Oceanography Accession Training assessment instrument used in the current study. Reliability analysis consisted of performing a Cronbach Alpha measure of internal consistency for the $\mathrm{N}=50$ item test for use as the pre and posttest assessment measure. The reliability coefficient from the Cronbach Alpha calculation resulted 
in 0.90 indicating a highly reliable internal consistency measure for the instrument.

\subsection{Validity Discussion}

A Factor Analysis was performed on the instrument prior to the current study resulting in 10 factors emerging from the instrument as compared with the eight factors (subscales) designated by the original intent of the instrument from the naval developers of the instrument. However, the two factors that emerged from the Factor Analysis procedure each contained only one item with a loading below 0.50 indicating a very weak loading overall as a potential distinct factor. This slight deviation from the original instrument construct validity considerations was not considered to detract from the findings of the study.

\section{Analysis of Data}

Analysis of data procedures conducted during the study aligned with each of the specific research hypotheses addressed by the study. Each hypothesis is discussed relative to the specific procedures used for analyzing pertinent data.

\subsection{Hypothesis One}

There is a significant mean change in the positive direction from pretest to posttest scores for each of the subscales identified on the Basic Oceanography Accession Training test instrument used in the study. Null Hypothesis One: There is no significant mean change in the positive direction from pretest to posttest test scores for each of the subscales identified on the Basic Oceanography Accession Training test instrument used in the study. The analysis of data procedure, the dependent $t$-test, was used to analyze the data for determining mean changes from pre to posttest tests for each of the eight subscales of the Basic Oceanography Accession Training test.

\subsection{Hypothesis Two}

There is a significant mean difference between males and females on the various posttest subscales of the test when pretest differences are controlled. Null Hypothesis Two: There is no significant mean difference between males and females on the various posttest subscales of the Basic Oceanography Accession Training test when pretest differences are controlled. The analysis of data procedure, Analysis of Covariance (ANCOVA), was used to analyze the data for determining mean differences between genders on the eight posttest subscales with pretests used as the covariates.

\subsection{Hypothesis Three}

Hypothesis three consists of three components: (a) There is a main effect mean difference in posttest subscale scores for ACC when gender is also considered; (b) There is a main effect mean difference in posttest subscale scores for gender when ACC is also considered; and (c) There is an interaction effect in mean differences when ACC and gender are considered simultaneously. Null Hypothesis Three: (a) There is no main effect mean difference in posttest subscale scores for ACC when gender is also considered; (b) There is no main effect mean difference in posttest subscale scores for gender when ACC is also considered; and (c) There is 
no interaction effect in mean differences when ACC and gender are considered simultaneously. The analysis of data procedure, Multiple Analysis of Variance (MANOVA), was used to analyze mean differences in posttest subscales scores with Academic Category Code (ACC) and gender as considerations.

\subsection{Hypothesis Four}

There is a relationship between length of service (in years) and posttest test scores. Null Hypothesis Four: There is no relationship between length of service (in years) and posttest test scores. The analysis procedure, the Pearson Correlation Coefficient, was utilized to analyze relationships between length of service and Basic Oceanography Accession Training test scores.

\section{Results}

Each of the four hypotheses is restated relative to the results of the data analysis procedures.

\subsection{Hypothesis One Results}

There is a significant mean change in the positive direction from pretest to posttest test scores for each of the subscales identified on the Basic Oceanography Accession Training test instrument used in the study. Hypothesis one was supported as indicated in the results presented in Table 1.

Table 1. Results of the dependent $t$ test procedures for each subscale $(\mathrm{N}=45)$

\begin{tabular}{|c|c|c|c|}
\hline Subscales & $\begin{array}{l}\text { Pretest } \\
\text { Means }\end{array}$ & $\begin{array}{l}\text { Post Test } \\
\text { Means }\end{array}$ & $\begin{array}{l}\text { Significance } \\
\text { levels }\end{array}$ \\
\hline Meteorological Satellite & 1.9 & 1.9 & $\mathrm{NS}$ \\
\hline Weather Surveillance Radar 1988-Doppler & 2.2 & 2.8 & $<.01$ \\
\hline Skew-T Log P Diagram & 0.9 & 1.5 & $<.01$ \\
\hline Surface Weather Observations & 0.8 & 1.2 & $<.01$ \\
\hline Environmental Codes & 0.7 & 0.9 & NS \\
\hline Atmospheric Physics and Dynamics & 3.4 & 2.9 & NS \\
\hline Numerical Weather Prediction & 1.2 & 1.3 & NS \\
\hline $\begin{array}{l}\text { Forecasting Weather Elements and Convective Severe } \\
\text { Weather }\end{array}$ & 1.2 & 1.0 & NS \\
\hline Total Score & 45.3 & 71.7 & $<.001$ \\
\hline
\end{tabular}

Basic Oceanography Accession Training Students' Pretest and Post Test Mean Changes

Significant $(\mathrm{p}<.01)$ positive changes from pre to posttest assessments were found for the subscales of Weather Surveillance Radar 1988-Doppler, Skew-T Log P Diagram, Surface Weather Observations, and Total Score as indicated in Table 1. Resulting significant mean changes for the overall performance of Basic Oceanography Accession Training students with specific emphases within three of the weather subscales of the Basic Oceanography Accession Training test outcomes indicate a sound focus on technology and simulation as an integral part of the training process.

\subsection{Hypothesis Two Results}




\section{Mll Macrothink}

Business and Economic Research ISSN 2162-4860 2013, Vol. 3, No. 1

There is a significant mean difference between males and females on the various posttest subscales of the Basic Oceanography Accession Training test when pretest differences are controlled. Results: Only one significant mean difference resulted from the investigation of all of the posttest subscales when the pretests were used as covariates. The resulting mean difference was found for Basic Oceanography Accession Training test Total score and is reported in Table 2.

Table 2. Results of the ANCOVA procedure by gender for posttest total scores $(\mathrm{N}=45)$

\begin{tabular}{|l|c|c|c|c|}
\hline \multicolumn{1}{|c|}{ Gender } & Means & Standard Deviations & F Value & Significance \\
\hline Male $(\mathrm{N}=21)$ & 69.3 & 12.8 & 3.4 & $<.10$ \\
\hline Female $(\mathrm{N}=22)$ & 74.7 & 12.2 & & \\
\hline
\end{tabular}

BOAT Students' Post Test Mean Differences by Gender with Pretests as Covariates

Significant mean differences were evidenced between male and female participants on posttest overall scores when pretest scores were used as covariates with female participants scoring significantly $(\mathrm{p}<.10)$ higher than males on the Basic Oceanography Accession Training test Total score. Although the almost 50-50 distribution of males and females in Table 2 do not reflect the approximately $75 \%$ to $25 \%$ male to female ratio for the gender composition of most military branches, the current study results provide some insight for future increases in women in the military who pursue science, technology, engineering, and mathematics (STEM) related programs of study and training. Substantial increases in women in the military, especially in the Navy, who are actively pursuing STEM related careers, provided the impetus for the investigation of Hypotheses 2 and 3.

\subsection{Hypothesis Three Results}

Hypothesis three consists of three components: (a) There is a main effect mean difference in posttest subscale scores for ACC when gender is also considered; (b) There is a main effect mean difference in posttest subscale scores for gender when ACC are also considered; and (c) There is an interaction effect in mean differences when ACC and gender are considered simultaneously. Results are presented in Tables 3 and 4.

Table 3. Results of MANOVA on posttest scores for Academic Category Code (ACC) by gender $(\mathrm{N}=45)$

\begin{tabular}{|l|c|c|}
\hline \multicolumn{1}{|c|}{ Source of Variability } & F Value & Significance Level \\
\hline Main Effects by Academic Category Code (ACC) & 2.7 & $<.05$ \\
\hline Main Effects by Gender & 13.4 & $<.01$ \\
\hline Interaction Effects of ACC and Gender & 1.9 & NS \\
\hline
\end{tabular}

BOAT Students' Post Test Mean Differences with ACC and Gender Considered

Hypothesis Three (a) and (b) were supported but Hypothesis 3(c) focused on the interaction effects was not supported. Specific means and Basic Oceanography Accession Training students' test scores are presented in detail relative to gender and ACC participation in Table 4.

Table 4. Descriptive statistics for ACC by gender 


\begin{tabular}{|l|l|c|c|}
\hline Academic Category Code Classifications & Gender Affiliation & Means & Standard Deviations \\
\hline Meteorology/Atmospheric & Female (N=3) & 58.0 & 14.0 \\
& Male (N=6) & 66.7 & 11.6 \\
\hline Marine Science/Oceanography & Female (N=11) & 74.2 & 11.2 \\
& Male (N=9) & 74.9 & 12.8 \\
\hline Chemistry/Biology & Female (N=5) & 68.8 & 8.1 \\
& Male (N=2) & 86.0 & 2.8 \\
\hline Nuclear Engineering/Physics & Female (N=1) & 52.0 & 0.0 \\
& Male (N=3) & 81.3 & 8.1 \\
\hline Geology/Geography & Female (N=1) & 48.0 & 0.0 \\
& Male (N=4) & 75.5 & 13.4 \\
\hline Total Score & Female (N=21) & 68.3 & 12.8 \\
& Male (N=22) & 74.7 & 12.2 \\
\hline
\end{tabular}

BOAT Students' Post Test Means and Standard Deviations by Gender and ACC

Tables 3 and 4 results provide additional information to the Basic Oceanography Accession Training professional development planning team relative to future academic classifications considerations as well as gender participation considerations.

\subsection{Hypothesis Four Results}

There is a relationship between length of military service in years and posttest scores. Results: The resulting Pearson Correlation Coefficient for length of service and BOAT Total test scores was found to be $r=0.38, p<.05$ indicating a significant positive relationship between length of service and Boat Total test scores.

\section{Conclusions}

Four research questions guided the study. Specific research questions and hypotheses were generated from the study purpose and guiding framework influences of the Kirkpatrick Evaluation Model and the naval core curriculum considerations.

The first research question stated: Is there a significant mean change in the positive direction from pretest to posttest test scores for each of the subscales identified on the Basic Oceanography Accession Training test instrument used in the study? In hypothesis one, a significant mean change in the positive direction from pretest to posttest test scores for each of the subscales was identified on the Basic Oceanography Accession Training test instrument that was used in the study. Hypothesis one was supported as indicated by significant $(\mathrm{p}<.01)$ positive changes from pre to posttest assessments on the subscales Weather Surveillance Radar 1988-Doppler, Skew-T Log P Diagram, Surface Weather Observations, and Total Score. Implications of this finding for the Navy are two-fold. First, the use of a pretest-posttest assessment design is not the typical approach used in the setting of this study. Assessment protocol prior to this study for the Professional Development Center involved students "passing" courses rather than examining the learning gains within courses. Therefore, the use of the pretest-posttest design provides a new venue for evaluating professional development programs. Second, the pre assessment component allows Navy professional development trainers to discern initial cognition differences in the students relative to their respective background experiences and former educational efforts, a new training consideration implemented by this study. 


\section{Macrothink}

Business and Economic Research

ISSN 2162-4860

2013, Vol. 3, No. 1

The second research question, Is there a significant mean difference between males and females on the various posttest subscales of the Basic Oceanography Accession Training test when pretest differences are controlled? In the analysis of hypothesis two, only one significant mean difference resulted from the investigation of all of the posttest subscales when the pretests were used as covariates. The resulting mean difference was found for the Total Score when the pretest was used as the covariate. Implications of this finding for future recruitment by gender in the Navy and other military branches include considerations of the strong performance and increased participation of women in Navy STEM career pathways.

The third research question, "Is there a difference in mean posttest subscale scores for Academic Category Code classifications by gender?" utilized the Multiple Analysis of Variance procedure. The results of the analysis of data for research question three indicated the following: (a) There was a main effect mean difference in posttest subscale scores for Academic Category Code (ACC) when gender was also considered; (b) There was a main effect mean difference in posttest subscale scores for gender when ACC was considered; and (c) However, there was no significant interaction effect in mean Basic Oceanography Accession Training Total test score differences when ACC and gender were considered simultaneously. Therefore the results of hypothesis three (a) and (b) were supported but Hypothesis 3(c) for the interaction effects result was not supported. Implications of this finding provide empirical information that reinforces the clustered participation of females within specific academic categories and the need for increasing the distribution of participation of females across academic categories in addition to increasing the numbers of females who enter STEM-related careers within the Navy.

The fourth research question: "Is there a relationship between length of service (in years) and posttest scores of the $\mathrm{N}=45$ participants?" was analyzed using the Pearson Correlation Coefficient and was supported. That is, the results indicated a positive relationship between length of military service (in years) and posttest scores with the resulting correlation for length of service and posttest scores depicted by: $\mathrm{r}=0.38, \mathrm{p}<.05$ indicating a significant positive relationship. Implications of this finding provide two specific considerations for the Professional Development Center: (a) the training and educational enrichment provided by the Basic Oceanography Accession Training course assists in the fulfillment of participants' aspirations, personal prosperity, and the efficient operation of the entire Naval training department. In addition the finding provides some empirical evidence that participants' longevity or length of service indicators in the field supplemented by educational experiences and performance measures supply potentially strong motives for other naval employees to improve their educational levels and other competencies.

Assessment methods used in the evaluation of training programs to improve performance are of paramount interest for organizations dependent on training for preparing employees. An integral conclusion of this study was the full inspection of the curriculum that supports the basic oceanography accession training course. Key military personnel examined the curriculum from a new perspective using the information supplied by the current study results, e.g., the application of holistic approaches for training, rather than technologically-oriented specialized training is supported by the results of the study. Additionally, the findings lend 
support to the possibility of expanding the Basic Oceanography Accession Training course in multiple delivery modes, such as online, distance learning, and other types of training modalities. The resulting statistical analyses and interpretation of findings for the current study provided insight for military professionals who are involved in the curriculum development and training for the Basic Oceanography Accession Training course. Assessments utilized in this study were rigorously examined for reliability and validity considerations for the purpose of transferability of the study to future basic Oceanography accession training classes. In addition, the resulting research design and procedures utilized in the study offers a model for future Navy courses and training efforts. This study was the first attempt within this organization to determine quantifiable and meaningful relationships of data commonly produced by the training efforts. The resulting empirical evidence also provided justification and insight into the restructuring of the Basic Oceanography Accession Training course for future training efforts. This study set the stage for future research that connects assessments to learning outcomes. This connection provides military environments and businesses with useful information for determining training effectiveness outcomes and ultimately training efficiency outcomes.

The views expressed in this article are those of the author and do not necessarily reflect the official policy or position of the Department of the Navy, Department of Defense, nor the U.S. Government

\section{References}

American Society of Training \& Development (2009). The value of evaluation: Making training evaluations more effective. Alexandria, VA: Smith, D., Paradise, A., Edlund-Braun, J., Brusino, J., King, K., \& Mcleod, R. (Eds.). Alexandria, VA: ASTD

Bedingham, K. (1997). Proving the effectiveness of training. Industrial and Commercial Training, 29(3), 88-91. http://dx.doi.org/10.1108/00197859710165083

Bramley, P \& Kitson, B. (1994). Evaluating training against business criteria. Journal of European Industrial Training, 18(1), 10-14. http://dx.doi.org/10.1108/03090599410054290

Center for Personal and Professional Development (2012). Navy Leadership Competency Model (NLCM). https://www.netc.navy.mil/centers/cppd/News.aspx?ID=0

Chairman of the Joint Chiefs of Staff (2011). Universal Joint Task List (UJTL) policy and guidance for the armed forces of the United States. http://www.dtic.mil/cjes_directives/cdata/unlimit/3500_02.pdf

Chief of Naval Operations (2007). Universal Naval Task List (UNTL). http://doni.daps.dla.mil/Directives/03000\%20Naval\%20Operations\%20and\%20Readiness/03 -500\%20Training\%20and\%20Readiness\%20Services/3500.38B\%20Chapter\%201-2.pdf

Chmielewski, T. L. \& Phillips, J. J. (2002). Measuring return-on-investment in government: Issues and procedures. Public Personnel Management, 31(2), 225-237. 


\section{Macrothink}

Business and Economic Research ISSN 2162-4860 2013, Vol. 3, No. 1

Clements, C. J., \& Josiam, B. M. (1995). Training: Quantifying the financial benefits. International Journal of Contemporary Hospitality Management, 7(1), 10-15. http://dx.doi.org/10.1108/09596119510078162

Hamid, S. (2011). A study of the effectiveness of training and development programmes of UPSTDC, India -an analysis. South Asian Journal of Tourism and Heritage, 4(1), 72-82.

HR People (2012). Measuring training effectiveness. http://hrpeople.monster.com/news/articles/2736-measuring-training-effectiveness

Kerchner, M., Hardwick, J. C., \& Thornton, J. E. (2012). Identifying and using 'core competencies' to help design and assess undergraduate neuroscience curricula. The Journal of Undergraduate Neuroscience Education, 11(1), A27-A37.

Kirkpatrick, D. L. (1994). Evaluating Training Programs. San Francisco, CA: Berrett-Koehler Publishers, Inc.

Kirkpatrick, J. D. \& Kirkpatrick, W. K. (2009). Kirkpatrick then and now, a strong foundation for the future. Saint Louis, MO: Kirkpatrick Partners, LLC.

Naval Education and Training M-132A. (2010). Navy school house testing management manual. Pensacola: Naval Education and Training Command

Rae, L. (2010). Training programme evaluation. Retrieved from http://www.businessballs.com/trainingprogramevaluation.htm

Sentric Competency Management. (2010). How to measure training effectiveness. http://www.sentricocompetencymanagement.com/page11405617.aspx

Stern, G. M. (2011). Company training programs: What are they really worth? http://management.fortune.cnn.com/2011/05/27/company-training-programs-what-are-they-re ally-worth/

\section{Copyright Disclaimer}

Copyright reserved by the author(s).

This article is an open-access article distributed under the terms and conditions of the Creative Commons Attribution license (http://creativecommons.org/licenses/by/3.0/). 